\title{
COMUNICAÇÃO
}

\section{AVALIAÇÃO DA QUALIDADE DE VIDA DE PACIENTES COM DOENÇA DE CHAGAS SUBMETIDOS A TRANSPLANTE DE CORAÇÃO}

\author{
Myrian Sabbaga Amato, Vicente Amato Neto e David Everson Uip
}

\begin{abstract}
Analisamos a qualidade de vida de 11 pacientes com doença de Chagas, 26 a 126 meses após terem sido submetidos a transplante de coração. Essa condição, influenciável por diversos fatores e que não corresponde só ao prolongamento da existência, revelou sensivel aprimoramento, passando os entrevistados a contar com objetivos e a poder concretizar realizações, antes inacessiveis.
\end{abstract}

Palavras-chaves: Doença de Chagas. Transplante de coração. Qualidade de vida.

A prevenção primária da doença de Chagas depende da coibição dos mecanismos segundo os quais o Trypanosoma cruzi é transmitido às pessoas suscetíveis. Envolve a eliminação de triatomíneos de moradias por eles infestadas, por meio de inseticidas em programações adequadamente estipuladas, mas também tem nexo com o desenvolvimento social, capaz de evitar a participação desses vetores. Além disso, como enfoques preventivos, impõe-se incluir as medidas terapêuticas aptas a permitir maiores porcentagens e durações de sobrevidas, ao serem considerados os indivíduos mais intensamente acometidos. Tais procedimentos, que podem ser enquadrados no contexto de profilaxia secundária, são sobretudo os pertinentes ao tratamento da insuficiência cardíaca e de arritmias. Contudo, afigura-se viável ir mais longe, pela adoção de táticas de nível terciário de complexidade, representadas pelo transplante de coração (TC) e pela miocardioplastia.

Quando os enfermos têm grave cardiopatia, praticamente não mais controlável mediante emprego de terapêuticas convencionais, ocorre a conveniência de recorrer ao TC e em algumas poucas instituições esse recurso está sendo utilizado ${ }^{1}$.

Instituto do Coração do Hospital das Clínicas, da Faculdade de Medicina da Universidade de São Paulo.

Endereço para correspondência: Myrian Sabbaga Amato. Av. Dr. Enéas de Carvalho Aguiar 44, 05403-900, São Paulo, SP, Brasil.

Recebido para publicação em 12/07/96.
Até o momento, no Instituto do Coração do Hospital das Clínicas, da Faculdade de Medicina da Universidade de São Paulo, foi realizado o maior número de TC relacionados com doença de Chagas. Desde 1985 tiveram lugar 21, em programa sistematicamente desenvolvido, no âmbito do qual deversas afecções compareceram como motivadoras da conduta cirúrgica em questão.

Nos meses de fevereiro e março de 1996 decidimos analisar a situação dos pacientes com doença de Chagas, submetidos ao TC e que estavam vivos (Tabela 1). Acima de tudo, procuramos obter informes a respeito das condições de vida de cada um deles, especialmente em termos de qualidade. Agimos por intermédio de entrevistas com os membros da casuística e, apenas ocasionalmente, em contato telefônico, mormente quando muito distantes as respectivas residências.

Tabela 1- Informações sobre os pacientes com doença de Chagas submetidos a transplante de coração.

\begin{tabular}{lccc}
\hline Paciente & Sexo & $\begin{array}{c}\text { Idade } \\
\text { (anos) }\end{array}$ & $\begin{array}{c}\text { Sobrevida após transplante } \\
\text { de coração* (meses) }\end{array}$ \\
\hline O.M.V. & M & 54 & 126 \\
S.M.C. & M & 64 & 108 \\
J.R.A.C. & M & 39 & 57 \\
A.S.N. & M & 55 & 73 \\
J.P.G. & M & 61 & 42 \\
C.C.C. & M & 17 & 39 \\
D.A.M. & M & 34 & 36 \\
B.P. & M & 40 & 15 \\
M.L.A.C. & F & 34 & 17 \\
J.J.S. & M & 35 & 39 \\
M.O.F. & M & 33 & 29 \\
M = masculino; F $=$ feminino. & \\
* na época da entrevista. &
\end{tabular}


Comunicação. Amato MS, Amato Neto V, Uip DE. Avaliação da qualidade de vida de pacientes com doença de Chagas submetidos a transplante de coração. Revista da Sociedade Brasileira de Medicina Tropical 30:159160, mar-abr, 1997.

Conforme as informações obtidas, pudemos globalmente deduzir que os pacientes com doença de Chagas, tratados por meio de TC, revelaram melhorias quanto aos limites de ações e de perspectivas de vida, passando a contar com objetivos e a poder concretizar realizações, antes inacessíveis. As qualidades das respectivas vidas não atigiram estágio ótimo; contudo, tiveram sensíveis aprimoramentos.

Qualidade de vida é preocupação atual de todos os que se preocupam com o bem-estar das pessoas. Não deve ser medida apenas pelo prolongamento da existência, pois influem diversos fatores, tais como saúde, moradia, trabalho, lazer e satisfação, além de outros².

Não é possível padronizar qualidade de vida, pois ela tem conotação individual, dependendo dos objetivos, das metas traçadas e dos anseios de cada um.

Mesmo levando em conta essas ponderações, constatamos benefícios propiciados aos entrevistados, traduzidos pela consecução de pelo menos alguns dos marcadores da qualidade de vida.

Em determinada época, uns poucos contestaram a efetivação de TC em enfermos com doença de Chagas e grave mocardiopatia. Alegaram que se trata de modalidade assistencial cara e acessível a poucos. Felizmente essa argumentação agora não é mais repetida, porquanto profilaxia primária coresponde a um comportamento e a atenção aos já doentes, que não enveredaram para o risco de infecção tendo responsabilidade comportamental, afigura-se justa e necessária. O panorama hoje é sensatamente entendido, figurando o TC como providência desejável sob múltiplos pontos de vista e, como percebemos, inclusive a propósito da qualidade de vida. Almejamos que sucedam progressos técnico-científicos a fim de tornar esse tipo de tratamento ainda mais eficiente, para tanto havendo cooperação especialmente de melhores controles da rejeição e da reativação da parasitose devida ao T. cruzi que é contratempo indesejável, sem ter constituído, no entanto, causa de qualquer óbito ${ }^{34}$.

\section{SUMMARY}

Quality of life was evaluated in 11 patients with Chagas' disease 26 to 126 months after submission to beart transplantation. There was an objetive improvement in their quality of life, after the transplant.

Key-words: Chagas' disease. Heart transplantation. Quality of life.

\section{REFERÊNCIAS BIBLIOGRÁFICAS}

1. Bocchi EA. Análise dos resultados do transplante cardíaco para tratamento da miocardiopatia chagásica. Tese de doutorado. Universidade de São Paulo, São Paulo, SP, 1993.

2. Nobre MRC. Qualidade de vida.Arquivos Brasileiros de Cardiologia 64:299-300, 1995.

3. Uip DE. Infecções em 100 pacientes submetidos a transplante cardíaco. Tese de doutorado. Universidade de São Paulo, São Paulo, SP, 1993.
4. Uip DE, Amato Neto V, Strabelli TMV, Bocchi EA, Fiorelli AI, Stolf N, Jatene AD, Bellotti G, Pileggi F. Infecções em 100 pacientes submetidos a transplante cardíaco. Arquivos Brasileiros de Cardiologia 64:537-540, 1995. 